\title{
Applications of Assistive Tools and Technologies in Enhancing the Learning Abilities of Dyslexic Children
}

\author{
Anita Satapathy \\ B.Ed. Semester IV, Amity Institute of Education, Amity University, Uttar Pradesh (AUUP), India \\ Corresponding author: anita.an.satapathy@gmail.com
}

\begin{abstract}
Procuring proper education is the birth right of every individual. It is the terminal way to walkover all the personal and social problems and is significant to all as it plays very prime roles in every individual's life. So, all students regardless of any challenges they have, has to be placed in age-appropriate general education classes that are in their own neighbourhood schools in order to receive high-quality instruction, interventions, and supports that will enable them to achieve success in their life. In today's era technology is everywhere due to its wider applications. But there are specific tech tools that can help people who learn and ponder adversely and these are called assistive technology or AT which are often inexpensive easy to use and may range from low to high tech. Assistive tools and technologies are any devices, software's, or equipments that aid people to work around their challenges. It has a significant effect in helping students with disabilities progress towards the goals outlined on their Education Plans. It helps dyslexic students to save time and overcome from the challenges such as note taking and poor handwriting which allow them to demonstrate their abilities which are incredible. Also, to learn how to complete their task and bypass an area of difficulty. In this paper the author enumerates the various types of assistive tools and technologies which are helpful for dyslexic students who are having learning disabilities and these technologies includes computer program, tablet applications that provide text-to-speech speech-to-text word prediction capabilities graphic organizers and many more.
\end{abstract}

Keywords: Education, Learning Disability, Educational Technology, Assistive technology, Enhancement of learning

\section{Aim of Education}

Education plays a very significant role for every child irrespective of whatever challenges they are facing in their life whether physically or mentally because they are the future of the world and should be updated with current affairs that are happening in the world. They are 
the pillar of the nation. For building up the nation children are considered to be the weapons where with all their knowledge and education they build up. So, each and every child must be educated. As education is for all so includes the concept of inclusive education. Inclusive education is defined when all students, irrespective of any challenges they may have, are implanted in age-appropriate general education classes that are in their own nearby schools to receive high-quality instructions, interventions, and all sorts of supports from the teachers so as to enhance the overall teaching learning process that enable them to meet success in their life or they target which they have aspired. The school or the classroom operate on the premise which are based on the concept that students with disabilities should be as fundamentally competent as students without disabilities due to this reason all students can be full and active participants in the classrooms. Successful inclusive education happens primarily by some certain processes that is through accepting, understanding, and attending to student differences and diversity, which actually includes their holistic development which are physical, cognitive, academic, social, and emotional. The driving principle is to make all students feel welcomed, comfortable in expressing their feelings and is supported constantly whenever they require in their efforts.

\section{Learning Disability in Dyslexic Students}

Learning disability which is a broad term that elaborates particular kinds of learning issues. A learning disability can cause a person to have trouble in learning something and also while applying certain skills in his day to day life activities. These skills which are most often affected are reading, writing, listening, speaking, reasoning, and solving mathematical problems. Learning disabilities are not fixed for a person instead it varies from person to person. One person with one kind of Learning Disability may not have the same kind of learning issues as another person which possess some learning disability. One person may have torment with reading and writing. While another person with same problem of in disability of learning may have problems in understanding and solving the mathematical problems. Still another person may have sufferings in each of these areas, as well as with comprehending of what people are speaking about. Learning Disability is a cluster of disorders that strikes people's ability to either interpret of what they observe, experience or hear or to link, collect and consolidate information from various parts of the brain. These limitations can show up in numerous ways such as particular difficulties with written and oral languages, coordination, self-control, or attention. Such difficulties extend to schoolwork and can impede learning to read, write, or solve math. A learning disability biologically can be defined as a neurological disorder that affects the brain's ability to receive, process, store, and respond to external stimuli. Due to learning disability which also hampers students in acquiring basic academic skills which are essential for success at school and work, and for coping with life in general. For a teacher an important thing to be noticed is that when the educator comes to know that 
Applications of Assistive Tools and Technologies in Enhancing the Learning... . P

a child has some sort of learning disabilities it actually tells that the child is experiencing some difficulty in processing information. So, the teacher learn much more about the child before he/she can determine how much difficulty, or the type of difficulties, or the impact the disability has on specific academic subjects or on other tasks. There are many myths which are associated for the children having learning disabilities and everyone specially the teacher has to ignore these myths which are students having this disability issue are not very smart, are only academic in nature and do not affect other areas, cannot succeed in higher education etc instead of considering these myths the teacher should try her level best by adopting various strategies so as to resolve this problem in students to some extent. One of the categories of the learning disability students are dyslexic students which are a type of learning disability due to the consequences of neurological disorders in the human body. This problem includes the features such as in difficulties with accurate or fluent word recognition and by poor spelling and decoding abilities. The outcomes of these difficulties which are actually observable which comprises a deficit in the phonological components which means the sounds associated in the pronunciation of words of languages that is often unexpected in relation to other cognitive abilities and the provision of effective classroom instruction. What is the exact cause of dyslexia found in children and that too at a very early age is still not completely clear, but is still vague. But studies from anatomical and brain imagery displayed differences in the way the brain of a person with dyslexia develops and functions. Moreover, studies have been made and has been noticed that people with dyslexia have been found to have problems in language such as with identifying the separate speech sounds within a word or identifying and acquiring how letters represent those sounds, a key factor in their reading difficulties. Lack of intelligence or desire to learn doesn't define dyslexia but with appropriate teaching methods, students with dyslexia can learn easily and successfully. Dyslexia occurs in people irrespective of whatever backgrounds and intellectual levels they have. It may also happen that people facing with dyslexia issue can be very bright the reason being that they are often capable or have been gifted in other areas such as art, computer science, design, drama, electronics, math, mechanics, music, physics, sales, sports or other technical areas.

\section{Educational Technology}

Technology is defined in broader terms as the entities, both material and immaterial, synthesised by the application of mental and physical efforts in order to achieve some value. In this application based technology refers to tools and machines which are actually used to resolve real-world problems. Technology has actually made a major impact in the education system whether it can be the teaching-learning part or storage of any educational information or any administrative work which are happening in schools. So, considering the aspect of teaching-learning process which really got enhanced due to the contribution of technology like the use of smart boards in classrooms, the internet which has a major contribution as through 
this various gamified educational apps can be accessed which are helpful both the teachers specially the evaluation part as well as for the students while grasping or understanding the difficult concepts. The use of MS office, specially the power point presentation which are actually useful for higher grade level students and nowadays one of the most prominent technology called the disruptive technology had a profound effect on the development of education which includes the artificial intelligence, robotics, drones and many more. Like the artificial intelligence which includes the plagiarism checkers are widely used in the field of education, Robots are used in labs for demonstrating the experiments for better understanding of concepts by the students. Now this technology also helped the students having learning disability problems specially emphasizing on the dyslexic students and these are called as assistive technologies which are elaborated in the coming section.

\section{Assistive Technology}

As we are finding a lot of applications of the technology in all the fields specially in education system and one of the most prominent technology called assistive technology which are specific technology tools including low tech tools, inexpensive in nature that aids people to learn and ponder differently. Assistive Technology can be defined as any device, software, or equipment that helps people to work around their existing challenges so that they can learn, communicate, interact, comprehend and function better. These technologies also help people who have difficulty in speaking, typing, writing, remembering, pointing, seeing, hearing, learning, walking, and many other things which they are incapable of doing it. Different disabilities require different assistive technologies as per the tools mentioned above. Further, these assistive technologies can be categorized into various types such as tools which are high-tech, special-purpose computers, hardware prosthetics, mounting systems, and positioning devices. Assistive Technology can be computer hardware including special switches, keyboards, and pointing devices. It can be computer software that includes screen readers and communication programs. It can be inclusive or specialized learning materials and curriculum aids. It can be specialized curricular software. These tools can be much more electronic devices, wheelchairs, walkers, braces, educational software, power lifts, pencil holders, eye-gaze and head trackers, and much more. This is especially essential and important for those kids who struggle with learning anything whether in reading, writing, or other LSRW skills (listening, speaking reading, writing), solving any mathematical problems, or understanding another subject. These tools can help these kids thrive in school and in life. And that can help to grow their level of confidence and be independent in their life.

\section{Application of Assistive Technology for Dyslexic Children}

Assistive technology, which has become a crucial aid to dyslexics who are at classroom or even in the workplace. These tools and technologies can be software, hardware or devices that 
Applications of Assistive Tools and Technologies in Enhancing the Learning... . P

ensure independence and productivity for the day-to-day life of the users. Assistive technology helps dyslexics people to save their time and overcome from the various challenges which they have, such as slow note taking and poor handwriting, allowing them to demonstrate their abilities in diverse ways that were once unimaginable for them.

Coming to various types of assistive technology starting from Speech Recognition Software which allows users to dictate or talk to a computer that uses software to convert this to text. This is clearly of interest to individuals that might otherwise have difficulty with spelling or writing emails, reports or other written communications. Then coming to Text-to-Speech software that can read emails, web pages, PDFs and Office documents in natural sounding voices. They also provide highlighting tools, spell and homophone checkers, which can enable independence when producing and proofreading their own work. Reader Pens which are becoming popular products nowadays in schools as they allow the user to process sentences quickly and understand the context of the sentences. A smallest portable device called reader pen that traces over a printed sentence and then reads back the words. There are also exam approved versions available, which can help students and create a level playing field in tests. Mind mapping software which is specifically designed to allow dyslexics students to plan their work more effectively. Those who have in spelling problem for them Spell Checkers that are specifically designed with dyslexia in mind to automatically make corrections to written communications. There are also tablets, smart phones and other applications that include a wide range of hardware platforms and software applications that can aid individuals to manage their time and list the task more effectively or work in conjunction with the other hardware devices such as smart pens. Computer based learning programs which are specifically written for dyslexics and can help to sharpen their skills in reading, writing, touch-typing and numeracy.

So, in education the most widely used assistive technologies are listening to audio books where a book is chosen that we want for a child to read and listen to it together by showing them how to mark their progress whether by the track number on the CD player or on a digital recording. The nice thing about digital audio book is that your place is atomically saved. If your device offers immersion reading where the text is highlighted as it is read, show them how to follow along. For building reading fluency this method of ear reading is fantastic. Audio books can be used for assignments too. Basically reading out loud to the listener the Text-to-Speech apps are helpful to convert text to speech and are often used for converting text found online into voice making learning via the Internet easier. Web-based Text-toSpeech Resources, Chrome Google Chrome, has a wide variety of Chrome Extensions that help dyslexic students with learning. They can perform numerous functions that are helpful to dyslexic students, including dictation, word prediction and text-to-speech,. Extensions are found and downloaded from the Chrome Web Store, are collected and managed in a dedicated tab of the browser. Microsoft One Note Free download which actually contains a variety 
of inclusive technologies such as speech-to-text, text-to-speech, and an immersion option that highlights text as it is read. Natural Reader which converts text from Docx, PDF,and text documents into amazing and surprising natural sounding speech. It Can be used on desktop computers, tablets or phones. Not only this we can also create and save audio files from converted docs to listen to later. Online OCR converts text in image files into digital text files using optical character recognition (OCR) where children just have to upload a file by entering a Captcha code and atlast pressing convert button. Once converted, the files can then be read aloud with text-to-speech. A text can be simplified with the help of Rewordify to make it easier to understand. The process is initiated where kids paste text or a web page address into the tool. The difficult words are replaced by Rewordify in the text or web page with simpler words or definitions. Kids can choose their reading level in the tool's settings. They can also choose how the simplified text is displayed.

The assistive technologies are also widely used in the classrooms in various forms such as Electronic Worksheets where students having dyslexia problem can use electronic worksheets to complete their assignments. These worksheets actually help students to line up words, equations and numbers on their assignments. Text-to-speech or speech synthesizing technology is even available on some of the worksheets. Further, there are various apps such as Learning Ally which is a great resource for audio books. This app consists of hundreds of books for kids and teens available with a monthly subscription. Users can follow along and adjust the size or type of text to make it easier for dyslexic students. Natural Reader another app which has a nice, natural-sounding voice that can read a variety of documents. Dyslexia Quest Dyslexia Quest is an app which is a kind of game based app, but is designed to help dyslexic kids and teens work on memory skills, phonics, and sequencing which means all the skills that dyslexic students typically struggle with. Sound Literacy for younger students with dyslexia, Sound Literacy is a fun app with game like activities designed to help students learn to recognize letter sounds. A more sophisticated word processor called Ginger Page that can help dyslexic students write flawlessly. OpenWeb OpenWeb is a web browser which allows dyslexic students to read with less difficulty by converting text into a dyslexic-friendly font. When text-to-speech is unnecessary or disruptive this browser is very helpful. Reading Intro by Oz Phonics another great app for young students with dyslexia, Reading Intro by Oz Phonics helps kids to learn while recognizing letter sounds. For dyslexic students, traditional note-taking is difficult so, MindMeister app was developed which allows users to create graphic organizers or mind maps to jot down their thoughts quickly and easily.

\section{CONCLUSION}

Learning disability which is a broad term that elaborates particular kinds of learning issues. A learning disability can cause a person to have trouble in learning something and also while applying certain skills in his day to day life activities. One of the categories of the learning 
Applications of Assistive Tools and Technologies in Enhancing the Learning... . P

disability students are dyslexic students which are a type of learning disability which includes the difficulties with accurate or fluent word recognition and by poor spelling and decoding abilities. As technologies are been used widely in the present era which are not only helpful for normal students but also to the students facing with the challenges of dyslexia. So, this technology called assistive technology has helped to these children during self paced learning or in the classrooms with the support of their teacher to overcome their problem of learning due to their disability to some extent with the help of various tools such as software's, pens, electronic worksheets, apps which not only made their life easier in learning, understanding the difficult concepts or solving the math problem but also increased their level of self confidence and made them capable of being independent.

\section{REFERENCES}

Boland, N. 2020. Assistive Technology Industry Association. Retrieved from https://www.atia.org/at-resources/ what-is-at/.

Cochran, J. 2016. How Can Assistive Technology Support Dyslexia. Retrieved from https://www.dyslexic.com/blog/ how-can-assistive-technology-support-dyslexia/

Dale, L. 2017. Inclusive Education. Retrieved from https://education.cu-portland.edu/blog/classroom-resources/ inclusive-education/.

Dennis, O. 2007. Evolution of Modern Humans. Retrieved from https://en.wikipedia.org/wiki/Technology.

Duartey, L. 2016. How important is education?. Retrieved from https://www.quora.com/Why-is-educationimportant-to-children .

Holmes, J. 2020. The Dyslexia Association. Retrieved from https://www.dyslexia.uk.net/services/assistivetechnology/.

Kaizen, C. 2020. Home Schooling with Dyslexia. Retrieved from https://homeschoolingwithdyslexia.com/blog/.

Kauffman, H. 2019. National Education of Special Education Teachers. Retrieved from https://www.naset.org/ index.php?id=2522.

Kilmartin, L. 2020. Masters in Special Education. Retrieved from https:/www.masters-in-special-education.com/ lists/5-examples-of-assistive-technology-in-the-classroom/.

Lynch, M. 2020. Apps and Tools for Dyslexic Students. Retrieved from https://www.thetechedvocate.org/11-mustapps-tools-dyslexic-students/.

Martin, J. 2020. Assistive Technology for Learning: What You Need to Know. Retrieved from https://www.understood. org/en/school-learning/assistive-technology/assistive-technologies-basics/assistive-technology-what-it-isand-how-it-works.

Moats, L. 2013. Dyslexia in the Classroom. Retrieved from https://dyslexiaida.org/wp-content/uploads/2015/01/ DITC-Handbook.pdf.

Sally, E. 2017. Yale Centre for Dyslexia and Creativity. Retrieved from https://dyslexia.yale.edu/resources/toolstechnology/. 
